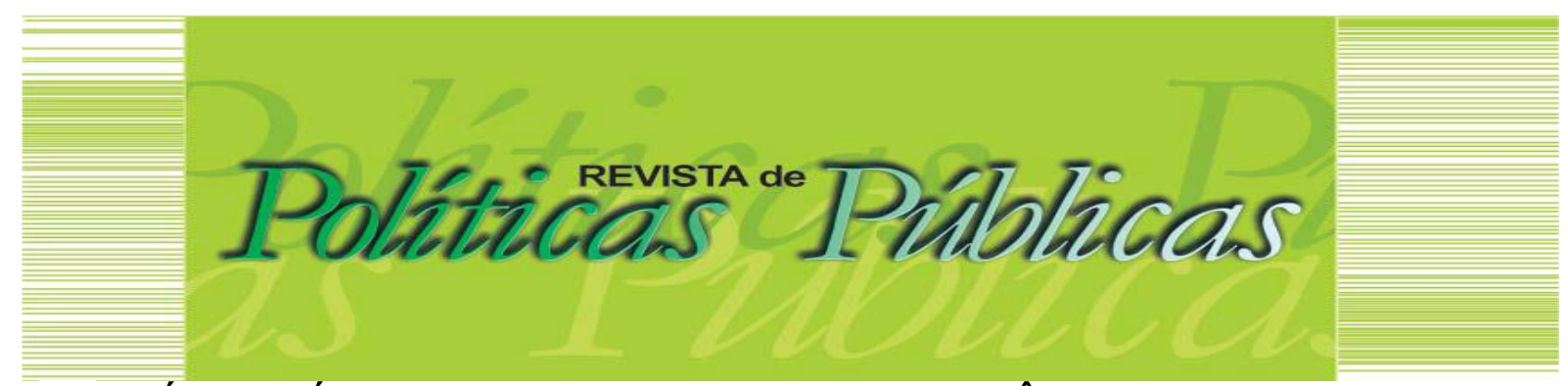

\title{
AS POLITICAS PÚBLICAS CULTURAIS NO CONTEXTO PANDÊMICO: uma análise comparativa entre Brasil e América Latina
}

\author{
Mariana de Araujo Aguiar ${ }^{1}$ \\ Luciana de Araujo Aguiar²
}

\section{Resumo}

Este ensaio tem por objetivo analisar as ações do governo brasileiro em relação a outros países da América Latina (Chile, Peru, Argentina e Cuba), principalmente, no que tange às políticas emergenciais para o setor cultural, durante os primeiros seis meses de pandemia da COVID-19. A pesquisa se pautou em análises de instrumentos jurídicos, canais de comunicação e análise bibliográfica. A partir do estudo, verifica que, apesar de diferentes formas de Estado e questões políticas, os países pesquisados, com exceção do Brasil, tiveram uma ação efetiva dos ministérios da cultura para coordenar e promover ações emergenciais ainda no primeiro semestre de 2020.

Palavras-chave: Covid-19. Políticas culturais. América Latina..

CULTURAL PUBLIC POLICIES IN THE PANDEMIC CONTEXT: a comparative analysis between Brazil and Latin America

\section{Abstract:}

This paper aims to analyze the actions of the Brazilian government in relation to other Latin American countries (Chile, Peru, Argentina and $\mathrm{Cuba}$ ), especially in regard to emergency policies for the cultural sector during the first six months of the COVID-19 pandemic. The research was based on analyzes of legal instruments, communication channels and bibliographic analysis. From the study, it was found that, despite different forms of state and political issues, the countries surveyed, with the exception of Brazil, had effective action by the ministries of culture to coordinate and promote emergency actions in the first half of 2020.

Keywords: COVID-19. Cultural policies. Latin America

Artigo recebido em: 21/12/2020 Aprovado em: 27/05/2021 DOI: http://dx.doi.org/10.18764/2178-2865.v25n1p63-82

\footnotetext{
1 Historiadora e economista. Doutora em políticas públicas pela Universidade Federal do Rio de Janeiro (UFRJ). Email: profmarianaguiar@gmail.com

2 Antropóloga. Doutora em Antropologia pela Université Paul-Valery - Montpellier III. Email: aguiar_luciana@hotmail.com
} 


\section{INTRODUÇÃO}

A América Latina é uma das regiões mais afetadas pelo coronavírus. Dentre os aspectos que podem explicar o alto número de contágio se encontram: o baixo investimento em saúde que, em 2018, por exemplo, situava-se em $2,2 \%$ do PIB regional, abaixo dos $6 \%$ recomendado pela Organização Pan-Americana da Saúde (CEPAL, 2020a, p. 10);o emprego informal que, de acordo com a Organização Internacional do Trabalho (OIT), em 2016, 53,1\% dos trabalhadores da região trabalhavam no setor informal (CEPAL, 2020a, p.11). E, por fim, o aumento dos índices de pobreza e extrema pobreza. Segundo o estudo da Cepal (2020b) em 2018, em torno de $30,1 \%$ da população regional estava abaixo da linha de pobreza e 10,7\% estavam na extrema pobreza.

Esses aspectos foram agravados pela pandemia, provocando a "pior crise econômica, social e produtiva que a região viveu nos últimos 120 anos e numa queda de 7,7\% do PIB regional" (CEPAL, 2021a, p.5). Isso implica um aumento na desocupação que, de acordo com o estudo da Cepal, a taxa de desocupação, em 2020, deve gerar em torno de 10,7\%. Este cenário tem uma influência direta no aumento da pobreza e da pobreza extrema no continente. A CEPAL (2021b) estimou que em 2020 a taxa de pobreza extrema figurou-se em 12,5\% e a taxa de pobreza alcançou $33,7 \%$. Com isso, o número de pessoas pobres teria aumentado 22 milhões a mais do que no ano de 2019, totalizando209 milhões de habitantes da região.

Entre os setores econômicos mais afetados com a atual crise da COVID-19 nas Américas estão 0 setor do turismo e o setor cultural. Em relação ao setor cultural, a Organização das Nações Unidas para a Educação, a Ciência e a Cultura (UNESCO, 2020), em seu boletim "Culture e Covid-19: impactand responsetracker" de 29 de abril de 2020, aponta uma estimativa de que 1,4\% dos empregos na região da América Latina estão no setor cultural e serviços auxiliares, no entanto, há um grande número de trabalhadores informais que podem ser afetados mais ainda pela crise econômica.

A Unesco (2020) aponta, ainda, que 95\% dos cerca de 95.000 museus em todo o mundo fecharam suas portas e 13\% podem nunca mais reabrir. Além disso, o valor estimado de perdas para a indústria cinematográfica mundial no final de maio era de 10 bilhões de dólares. As indústrias culturais e criativas contribuem com 2.250 bilhões de dólares para a economia mundial ( $3 \%$ do PIB) e representam 29,5 milhões de empregos em todo o mundo.

Dada essa conjuntura, buscamos analisar as ações do governo brasileiro em relação a outros países da América Latina, principalmente, em relação às políticas culturais. Definimos como campo de análise, além do Brasil, quatro outros países latino-americanos: Argentina, Peru, Chile e Cuba. Estes foram selecionados a fim de comparar as políticas para reduzir o impacto da Covid-19 no setor cultural tanto de estados federalistas (como Brasil e Argentina) quanto estados unitários (Peru, 
Chile e Cuba), buscando compreender semelhanças e diferenças entre as ações estatais para o campo cultural.

\section{O FEDERALISMO BRASILEIRO E AS POLÍTICAS CULTURAIS NOS PRIMEIROS SEIS MESES DE PANDEMIA DA COVID-19}

O Senado Federal aprovou, em 20 de março, o decreto legislativo que reconhece o estado de calamidade pública no Brasil em decorrência da pandemia do coronavírus (BRASIL, 2020a). № entanto, o governo federal adotou uma postura de negacionismo da doença, ignorando os protocolos da Organização Mundial da Saúde. As medidas de estabelecimento de quarentenas e de medidas de distanciamento social e de uso de máscaras foram estabelecidas por governadores e prefeitos. Em pronunciamento, no dia 24 de março, o presidente Bolsonaro criticou governadores por determinarem quarentena - com fechamento de comércio e barreiras sanitárias entre municípios - questionou 0 motivo pelo qual escolas foram fechadas e criticou a imprensa (BOLSONARO..., 2020).

A atitude negacionista tem tido drásticas consequências como: a instabilidade na gestão da saúde pública, o que acarretou a mudanças de dois ministros da saúde, durante o os primeiros seis meses da pandemia1; o crescente número de casos confirmados e mortos, o que levou o Brasil a ser o segundo país com maior número absoluto de casos², atrás apenas dos Estados Unidos (WHO, 2020); a demora em responder aos auxílios financeiros para pequenas e médias empresas e para a população de baixa renda.

No que tange a esse último, a proposta inicial do governo era um voucher de $\mathrm{R} \$ 200$ aos trabalhadores informais (POMPEU, 2020); esta foi ampliada pelo plenário através do PL 9.236/2017, aprovada pelo poder legislativo e sancionada pelo presidente no dia 02 de abril (BRASIL, 2020b). 0 auxílio emergencial de $\mathrm{R} \$ 600,00$ (em torno de 105 dólares) voltado para trabalhadores cuja renda familiar mensal per capita é de até $1 / 2$ (meio) salário-mínimo ou a renda familiar mensal total de até 3 (três) salários mínimos estava previsto, inicialmente, por 3 meses, foi prorrogado por mais 2 meses. E, no dia 01 de setembro, o governo decidiu prorrogar o auxílio até dezembro com um valor de $\mathrm{R} \$ 300,00$ (cerca de 54 dólares).

O negacionismo também refletiu nas reduzidas atuações do governo federal para o setor cultural, que se resumiram em ajustes de prazos para captação, execução e prestação de contas de projetos aprovados por leis de incentivo fiscal (BRASIL, 2020c); na minimização dos efeitos dos cancelamentos para o setor de turismo e setor de eventos (BRASIL, 2020d). No dia 19 de março foi anunciada pela ex-Secretária Especial de Cultura a primeira medida para lidar com as consequências da pandemia. Esta se refere aos projetos culturais, aprovados pelo Programa Nacional de Apoio à 
Cultura (Pronac). Entretanto, somente um mês após o anúncio, foi instituída a Instrução Normativa (IN) que estabelece os procedimentos extraordinários para captação, execução e prestação de contas de projetos aprovados por leis de incentivo fiscal. A IN n. 5, de 20 de abril de 2020 (BRASIL, 2020c), determinou, entre outras medidas, a liberação e movimentação de recursos abaixo do limite previsto (20\%) mediante justificativa; a ampliação do prazo de captação e execução prorrogáveis até dezembro de 2020 (art.3), flexibilizou a prestação de contas sem alterar, no entanto, os procedimentos e os prazos para isso.

Outro documento relativo ao Pronac é a IN n. 6, de 29 de abril de 2020 (BRASIL, 2020e), que apenas aponta o parcelamento e a suspensão por até 120 dias de débitos para os projetos culturais impactados pela Covid-19. Embora importantes estas medidas desconhecem que, devido ao fato de provocarem aglomerações de público, grande parte dos projetos aprovados pela lei de incentivo terão dificuldades para serem realizados, mesmo com as alterações nos prazos. Além disso, estas instruções normativas ignoram o grande número de artistas que não foram aprovados pela lei de incentivo, mas que dependem financeiramente da bilheteria dos eventos que foram anulados.

Uma segunda providência anunciada pela Secretaria Especial de Cultura diz respeito ao cancelamento de serviços turísticos e culturais durante ao período de calamidade pública, editada pela MP (Medida Provisória) 948, de 8 de abril de 2020 (BRASIL, 2020d). A minuta da MP tem como argumento a minimização dos efeitos dos cancelamentos para o setor de turismo e setor de eventos. Embora cite os serviços culturais, principalmente os atrelados aos shows e espetáculos (art. 2), e destaque que os artistas já contratados não possuem obrigação de restituir o valor recebido, desde que o evento seja remarcado (art.4), a legislação tem uma maior preocupação com o setor turístico e direito ao consumidor, o que se evidencia na exposição dos motivos assinada pelos proponentes da minuta. Além do mais, a MP é restrita na definição da classe artística já que considera, apenas, os seguintes eventos: shows, rodeios, espetáculos musicais e de artes cênicas (art.4), excluindo manifestações como: artesanato, literatura, audiovisuais, e não expressa nenhuma preocupação em relação aos eventos produzidos pelos grupos de cultura popular.

Em meio às ausências de políticas públicas mais efetivas para o setor cultural, a exsecretária de cultura, a atriz Regina Duarte, foi confrontada com críticas a sua gestão em entrevista ao canal CNN Brasil, no dia 07 de maio de 2020. Esta foi considerada polêmica, pois a ex-secretária minimizou as mortes ocorridas no período da ditadura militar (1964-1985) e, além disso, encerrou abruptamente a entrevista após se irritar com os questionamentos feitos pela atriz Maitê Proença a respeito das ações para socorrer a classe artística nesse período. A repercussão dessa entrevista foi tamanha, que no dia seguinte foi elaborado um manifesto assinado por mais de 500 artistas em repúdio 


\section{AS POLÍTICAS PÚBLICAS CULTURAIS NO CONTEXTO PANDÊMICO: uma análise comparativa entre Brasil e \\ América Latina}

à fala de Duarte. Esse foi um dos fatores que levou à exoneração da atriz do cargo, anunciada no dia 20 de maio e publicada em diário oficial apenas no dia 10 de junho.

Após a saída de Regina Duarte, foi nomeado, no dia 19 de junho, 0 ator Mário Frias para ocupar a pasta. Ele tomou posse no dia 23 de junho. Essa troca de secretários indica a instabilidade da pasta da cultura $^{3}$ que afeta a dinâmica de funcionamento interno, o processo de produção e implementação de políticas públicas, dentre outros aspectos. A literatura tem ressaltado que a instabilidade gerada por turnover ministerial provoca incentivos negativos à manutenção da burocracia e rompimento das relações de accountability entre políticos e burocratas com o fraco acúmulo de experiências (HUBER, 1998; MARTÍNEZ-GALLARDO, 2010 apud PALOTTI, 20017)

Portanto, a rotatividade na gestão gera um desgaste na burocracia, o que Huber e Lupia (2001 apud CODATO et al, 2018) caracterizam como dilema das expectativas da vida burocrática porque os servidores públicos que atuam no âmbito burocrático não sabem se seus esforços serão compensados ou se serão punidos, gerando uma descrença na continuidade das ações. Assim, há a necessidade de uma adaptação da burocracia à nova gestão, ocasionando perda temporal. No caso analisado, o turnover nos indica uma exacerbação das reduzidas ações do poder executivo federal às demandas do setor cultural.

No entanto, a resposta para o setor cultural, no âmbito federal, começou a ser debatida pela Câmara dos Deputados, ainda em março, quando foi apresentado o projeto de lei 1075/2020 com o objetivo de estabelecer ações emergenciais destinadas ao setor cultural. 0 projeto tramitou na câmara até ser aprovado no dia 26 de maio, seguindo para o Senado que o aprovou no início de junho. A sanção do presidente ocorreu no dia 29 de junho de 2020. Mas, o decreto que regulamenta a lei (Decreto 10.564/2020) só foi publicado no dia 17 de agosto de 2020.

A lei 14.017/20204, denominada Lei Aldir Blanc ${ }^{5}$, estipulou o repasse de 3 bilhões de reais (cerca de 569 milhões de dólares), sendo 50\% desse valor para estados e DF e 50\% para municípios (BRASIL, 2020f). A lei definiu as seguintes ações emergenciais: renda emergencial mensal de 3 parcelas de 600 reais aos trabalhadores e trabalhadoras da cultura; subsídio de, no mínimo 3.000 reais e no máximo 10.000, para manutenção de espaços artísticos e culturais e micro e pequenas empresas; e editais, prêmios, chamadas públicas destinadas à manutenção de agentes, cursos, de produções culturais, bem como de realização de atividades artísticas e culturais que possam ser transmitidas pela internet.

A medida, apesar de importante, denota o quanto o processo legislativo é moroso em relação a uma ação mais enérgica do executivo Cabe ressaltar que o legislativo, durante o período pandêmico, intensificou seu protagonismo, aprovando uma série de medidas que não foram propositivas pelo poder executivo. Esse aspecto evidencia um conflito entre os dois poderes que, 
segundo a análise de Almeida (2020), reflete tanto um fator conjuntural, na medida em que o presidente não possui uma posição majoritária no congresso, mas também um fator estrutural que remete à mudança de padrão legislativo que vem ocorrendo desde 2008 no Brasil. No entanto, a inabilidade de negociação do atual governo é um dos aspectos que levam à exacerbação desse conflito.

Essa mesma inabilidade também foi analisada na coordenação federativa. 0 federalismo pós-Constituição Federal de 1988 foi baseado em um modelo compartilhado, combinando autonomia subnacional com coordenação nacional. Assim, coube à União normatização e financiamento de políticas com foco em sua expansão e no combate às desigualdades regionais ( $A B R U C I O$ et al, 2020). No entanto, desde a campanha eleitoral, 0 atual presidente tem contestado esse modelo. Com o slogan "Mais Brasil, Menos Brasília", Bolsonaro buscou implantar um federalismo dual, ou seja, autonomia dos entes federados, resultando em pouca atuação da União nas políticas públicas. Abrucio et al (2020) ressaltam que a concentração autocrática de decisões que afetam as instâncias subnacionais reforça a posição do federalismo dual, na medida em que dificulta o diálogo e privilegia o confronto intergovernamental.

Essa postura dualista foi analisada nas ações de combate ao Covid-19. A desarticulação Federalista levou a um protagonismo dos estados frente à União; muitos deles promoveram arranjos de coordenação, como comitês, conselhos e etc, com foco emergencial. 0 caso mais emblemático foi o Consórcio Nordeste, que reúne os estados da região nordeste do país e articulou um Comitê Científico, com foco em fornecimento de informações para a tomada de decisão (LINHARES; RAMOS; MESSENBERG, 2020). Assim, apesar das ações dos estados, a descoordenação federativa tem efeitos perversos no aumento da desigualdade regional e, como apontam Abrucio et al (2020), foi uma das causas para os péssimos resultados em relação ao número de doentes e mortos pela Covid.

No que tange ao setor cultural, os estados e municípios também exerceram protagonismo durante os primeiros meses de pandemia, frente à reduzida atuação da União, colocando em xeque o papel do Sistema Nacional de Cultura (SNC). Segundo a Emenda Constitucional n. 71/2012, que inclui o art. 216-A na Constituição Federal, o SNC "institui um processo de gestão e promoção conjunta de políticas públicas de cultura, democráticas e permanentes, pactuadas entre os entes da Federação e a sociedade" (BRASIL, 2012). Ele se baseia em princípios como o da integração e interação na execução de políticas culturais, da descentralização pactuada de gestão, recursos e ações. 0 principal mecanismo de financiamento do SNC é o Fundo Nacional de Cultura, que é um fundo de natureza contábil composto por recursos do Tesouro Nacional, doações, legados, subvenções e auxílios de entidades de qualquer natureza, entre outras fontes. Os recursos deste fundo podem ser transferidos aos estados, municípios e Distrito Federal para o desenvolvimento de programas e ações culturais. 


\section{AS POLÍTICAS PÚBLICAS CULTURAIS NO CONTEXTO PANDÊMICO: uma análise comparativa entre Brasil e América Latina}

O orçamento aprovado pela Lei Orçamentária Anual (LOA) de 2020 para o FNC foi de R\$ 890 milhões (BRASIL, 2020g) e, até junho, nenhum valor tinha sido empenhado, conforme o portal da transparência. Cabe destacar que, além desse orçamento, o FNC teve cerca de 345 milhões de superávit financeiro apurado no balanço patrimonial da União entre os meses de janeiro a dezembro de 2019, de acordo com a Portaria n 189 da Secretaria do Tesouro Nacional (BRASIL, 2020h). Cabe ressaltar, ainda, a reserva de contingenciamento do orçamento do fundo que tem se agravado ao longo dos últimos anos. De acordo com a LOA de 2020, de $\mathrm{R} \$ 890$ milhões, $54,58 \%$ desse valor foi contingenciado, aproximadamente, R\$ 486 milhões. Em 2019, o contingenciamento foi de, aproximadamente, $46,49 \%$ do orçamento do FNC, totalizando 637 milhões de reais, conforme observamos no gráfico abaixo:

Gráfico 1 - Reserva de Contingenciamento do Fundo Nacional de Cultura - em milhões de R\$

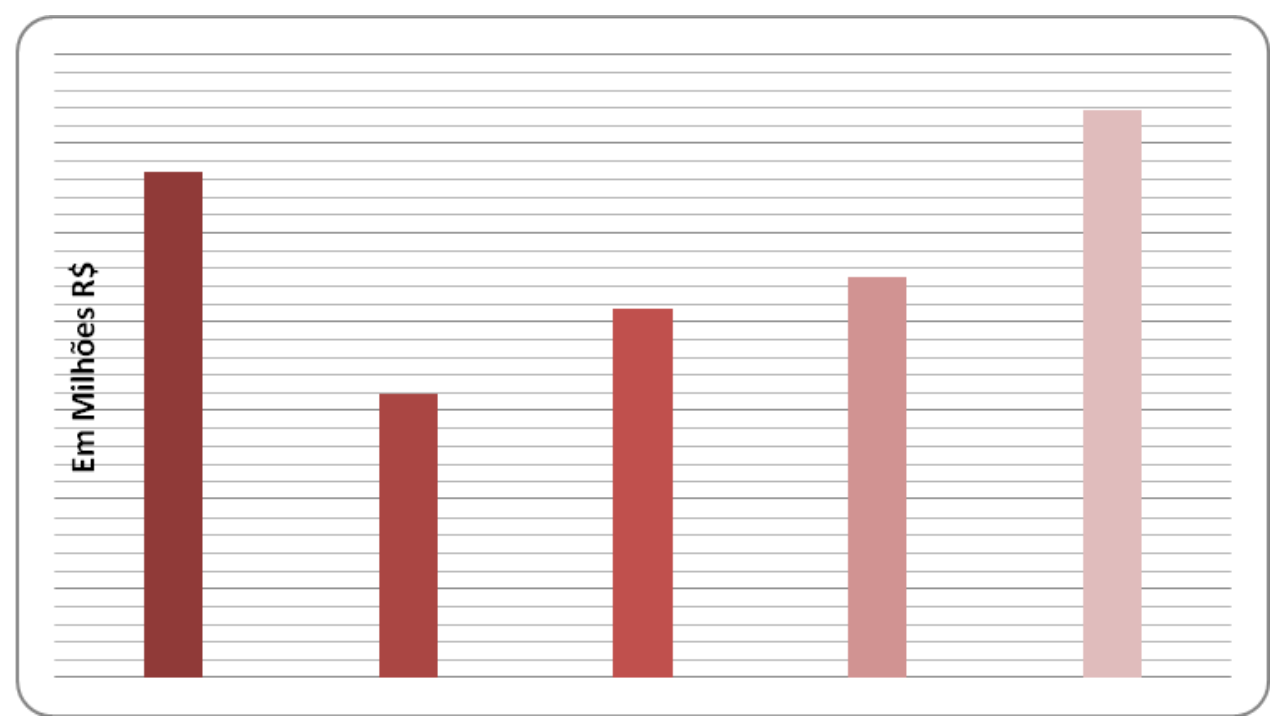

Fonte: Portal da Transparência(CGU, 2020). Elaboração própria.

Desse modo, considerando o crescente contingenciamento do orçamento do FNC e seu superávit observado no ano de 2019, podemos concluir que a utilização do orçamento foi irrisória. Cabe observar que o Decreto n. 5.761/06 (BRASIL, 2006) detalhou as modalidades de utilização dos recursos do fundo e, dentre elas, se encontra: "transferência a Estados, Municípios e Distrito Federal para desenvolvimento de programas, projetos e ações culturais, mediante instrumento jurídico que defina direitos e deveres mútuos" (Ibid.). Logo, a reduzida execução orçamentária do FNC, no ano de 2019 e nos primeiros meses do ano de 2020, reforça o federalismo dual, como apontou Abrucioet al (2020).

Durante os primeiros meses da pandemia, portanto, estados e municípios agiram mais rapidamente às necessidades do setor. O site da Confederação Nacional de Municípios (CNM, 2020) procedeu a um mapeamento de medidas dos estados para reduzir os impactos negativos da pandemia 
no setor cultural. A listagem, publicada no dia 25 de março e atualizada no dia 08 de abril, cita projetos como o Festival Te Aquieta em Casa, lançado pela Secretaria de Estado da Cultura do Pará que seleciona, por meio de edital, conteúdos culturais em formato digital nas áreas de artesanato, música, dança, teatro, contação de histórias, artes visuais e expressões culturais populares, afro-brasileiras, indígenas. Podemos encontrar também duas edições do edital Conexão Cultural, lançados pelo governo do Maranhão, para apresentações de artistas maranhenses por meio virtual. Outros estados como Paraíba, Ceará, Mato grosso do Sul, Amazonas, Espírito Santo, São Paulo, Rio de Janeiro, Piauí, Rio Grande do Sul, entre outros, promoveram editais nessa mesma linha.

Observa-se que, embora seja instituída pela emenda Constitucional n. 71/2012, o processo de gestão conjunta de políticas públicas ${ }^{6}$, a execução orçamentária do FNC para tal fim tem sido diminuta e, se evidenciou nos primeiros meses de estado de calamidade pública, quando estados e municípios agiram de forma isolada sem nenhuma coordenação federativa. A situação só foi modificada após a aprovação da Lei Aldir Blanc ${ }^{7}$ e sua regulamentação que possibilitou a transferência de recursos do FNC para estados e municípios.

3 PERU E CHILE: as ações governamentais em estados com poder central forte

Diferentemente do Brasil, os governos peruano e chileno reagiram de forma rápida à pandemia. No Peru, por exemplo, no dia 15 de março, 9 dias após se detectar o primeiro caso da doença, o governo de Martín Vizcarra decretou estado de emergência sanitária, fechou as fronteiras, promulgou toque de recolher para todas as cidades (CAMPOS, 2020). 0 governo chileno também adotou posturas semelhantes, 10 dias após o primeiro caso detectado no país; no dia 13 de março, o presidente SebastiánPiñera promulgou as primeiras medidas de controle da epidemia, como: fechamento de fronteira, toque de recolher das $22 \mathrm{~h}$ até as $05 \mathrm{~h}$ e as licenças temporárias de acesso a serviços básicos ${ }^{8}$ nos municípios em quarentena (PIÑERA..., 2020).

O governo peruano também foi ágil nas ações para mitigar os problemas econômicos. Através do decreto de urgência n. 27/2020, de 16 de março, o governo autorizou o subsídio monetário de 2 parcelas de 380 soles (o equivalente a 105 dólares) para famílias em condição de pobreza e extrema pobreza (CAMPOS, 2020). Além deste, o governo anunciou outros oito subsídios destinados a diferentes públicos vulneráveis (trabalhador independente, morador de zona rural, órfãos etc., inclusive para trabalhadores do setor da saúde) com valores entre 160 a 760 soles, divididos entre 1 a 2 parcelas. 0 exemplo mais emblemático é o bônus familiar universal de 760 soles (cerca de 210 dólares) dirigidos a famílias que possuem renda mensal abaixo de 3.000 soles, visando beneficiar 8,5 milhões de famílias peruanas ${ }^{9}$. 


\section{AS POLÍTICAS PÚBLICAS CULTURAIS NO CONTEXTO PANDÊMICO: uma análise comparativa entre Brasil e América Latina}

Já no Chile, o auxílio foi aprovado mais tardiamente. Em maio, o congresso chileno aprovou a lei que cria a Renda Familiar Emergencial (IFE), conforme a informação do portal oficial Chile (2020a). Esta lei foi modificada e ampliada e está atualmente (desde 31 julho) na sua terceira versão. Nesta, o benefício chega a 100.000 pesos (em torno de 128 dólares) para todo aquele que está inscrito no Registro Social da Família e que declara uma redução ou interrupção de sua renda. 0 valor total que cada família recebe é calculado de acordo com a renda que recebe atualmente (ROMÁN, 2020).

Apesar dessas ações, o Peru era o segundo país da América Latina com mais número de casos confirmadas ${ }^{10}$, no início de setembro. Se considerarmos o número de mortos por um milhão de habitantes, o Peru se encontrava no topo da lista dos países latino americanos e o Chile em terceiro lugar, segundo os dados de início de setembro ${ }^{11}$. Dentre as razões para tal questão, a reportagem de Bel (2020) destaca: a informalidade; casas superlotadas que, de acordo com a pesquisa Nacional de Famílias do Peru de 2019, 11,8\% das famílias pobres vivem em casas superlotadas com 5 ou mais pessoas vivendo em um quarto; além disso, os auxílios financeiros para a população levaram a aglomerações em bancos, uma vez que apenas $38,1 \%$ dos peruanos adultos possuíam conta bancária, segundo o relatório de inclusão financeira da Superintendência de Bancos e Seguros do Peru, de junho de 2019. Portanto, a realidade socioeconômica é um fator complicador para a questão pandêmica.

No Chile, o desconhecimento sobre as questões socioeconômicas e a debilidade de comunicação nos registros de casos de covid foram fatores da queda do ministro da saúde. De acordo com a cientista político Julieta SuárezCao, "o então ministro da Saúde chegou a dizer que não sabia que tanta gente vivia amontoada (em casas pobres e pequenas) no país e que por isso não podiam fazer o distanciamento social", como sublinha a reportagem de Márcia Carmo (2020a).

Em relação às medidas para o setor cultural, o Ministerio de las Culturas, las Artes y el Patrimonio do Chile (CHILE, 2020b) publicou em 23 de março de 2020 que destinaria 15 bilhões de pesos (em torno de 20 milhões de dólares) para apoiar artistas e organizações culturais pela crise do setor devido ao coronavírus. 0 Ministério lançou uma consulta pública a agentes e organizações culturais com o objetivo de receber informações necessárias para definir as emergências do setor e reformular a próxima chamada de Fundos Culturais.

A promoção da criação artística neste contexto foi estabelecida em parceria com as Secretarias Regionais Ministeriais (Seremi) ligadas ao Ministerio de las Culturas. Elas estabeleceram diversos editais a nível regional, abarcando diferentes áreas artísticas e da economia criativa. Cada edital foi constituído de maneira independente pela Seremi e cabe a ela determinar os objetivos da chamada, quem e quais áreas artísticas podem se inscrever, como se inscrever, os requisitos, os critérios de seleção, o comitê de avaliação e o valor do cachê. A Seremi de las Culturas, las Artes y el 
Patrimonio da Região de Valparaíso, estabeleceu, por exemplo, um cachê de valor bruto de $\$ 100.000$ pesos (em torno de 128 dólares) no edital dedicado às artes cênicas (CHILE, 2020c).

No Peru, o auxílio financeiro ao setor cultural só foi aprovado no dia 20 de maio por meio do Decreto de Urgência $n^{\circ}$ 058-2020 (PERU, 2020), que estabelece mecanismos para mitigar os impactos da pandemia sobre as atividades culturais. $O$ decreto autorizou a transferência de 50 milhões de soles (cerca de 14 milhões de dólares) para o Ministério da Cultura a fim de financiar: apoios econômicos a favor de pessoas físicas e jurídicas que realizam atividades culturais e aquisição de conteúdos culturais visando colocar à disposição dos cidadãos por meio de plataformas digitais e outros meios de difusão.

Em julho ,o Ministério da Cultura divulgou oito linhas de apoio financeiro dirigidas a trabalhadores/as e organizações culturais, assim como portadores/as do patrimônio imaterial. Além dessas linhas, o Ministério da Cultura divulgou editais visando à aquisição de conteúdos culturais divididos nas seguintes categorias: material audiovisual, material bibliográfico, material de artes cênicas, visuais e música, materiais de música e artes tradicionais.

Apesar de diferentes nuances, podemos observar que os dois países tiveram ações de maior protagonismo do executivo, comparado ao Brasil, o que se evidencia, também, pela presença de um ministério dedicado unicamente à cultura. No Peru, apesar de um quadro de disputas entre executivo e legislativo, a delegação de poderes legislativos ao Executivo foi aprovada com o objetivo de atender à emergência sanitária. No Chile, o governo de SebastiánPiñera viu sua popularidade aumentar após recorde histórico de 6\% em razão dos surtos sociais que ocorreram em outubro de 2019, no entanto, sua popularidade continua baixa, cerca de 24\% em junho (CHARLEAUX, 2020 ).

Portanto, podemos observar que em estados unitários, como Peru, Chile, o executivo já possui um poder centralizado, o que Ihes permitiu estabelecer ações emergenciais de maneira mais ágil. No entanto, cabe destacar, como no caso do Chile e Peru, que os conflitos políticos, o reduzido investimento em saúde e as questões socioeconômicas agravaram as consequências da pandemia.

\section{A COORDENAÇÃO FEDERATIVA NA ARGENTINA E O COMBATE AO CORONAVÍRUS}

A Argentina, diferentemente dos países analisados acima, conseguiu manter um número baixo de mortes associado ao coronavírus, pelo menos até o início de agosto ${ }^{12}$. 0 primeiro caso positivo da COVID-19 no país foi registrado no dia 03 de março. Até o início de agosto, o país registrou 196.543 casos do novo coronavírus e 3.612 mortes (CARMO, 2020b), abaixo de países com menor número de habitantes, como Chile e Peru. Dentre as razões para uma menor taxa de mortalidade pode ser explicada por uma sintonia entre governantes, que permitiu a adoção de um isolamento social 
preventivo e obrigatório em todo o país que entrou em vigor em 20 de março. Além disso, houve uma estratégia de comunicação massiva, o que levou grande parte da população a seguir os protocolos adotados. Apesar de ações rígidas de isolamento social, o governo argentino realizou poucos testes, comparados com outros países da América Latina. De acordo com Carmo (2020b): "a Argentina realiza 14 mil testes por milhão de habitantes, o Chile faz 81 mil e o Peru, 69 mil exames pela mesma quantidade de pessoas", o que pode ser um dos fatores do baixo número de casos confirmados no primeiro semestre.

Apesar de inicial apoio popular às ações governamentais, observa-se uma crescente exaustão do isolamento social, o que tem elevado o número de casos e mortes ${ }^{13}$ agravado pelos problemas estruturais no sistema de saúde do país como: a capacidade desigual dos serviços de saúde nos níveis nacional e subnacional (ONU, 2020). Somam-se, a isso, os graves problemas econômicos que a Argentina já enfrentava antes da pandemia. Segundo a publicação da ONU (2020), entre 2012 e 2019, o PIB per capita nacional caiu 11\% e, no segundo semestre de 2019, e a taxa de pobreza aumentou e alcançou, no segundo semestre de $2019,35,5 \%$ da população.

Nesse cenário, o governo adotou algumas medidas com foco em mitigar o impacto da pandemia na economia como: adiamento ou redução de até $95 \%$ do pagamento contribuições do empregador; pagamento pelo Estado de até $50 \%$ do salário dos trabalhadores do setor privado, 0 pagamento de 4 parcelas da Renda Familiar de Emergência (IFE) que se refere ao bônus de 10.000 pesos (equivalente a US\$135) destinado a pessoas desempregadas, trabalhadores informais, pessoas que recebem Abono Universal para Crianças ou Abono de Gravidez para Proteção Social.

No que tange às ações voltadas para o setor cultural, o Ministério da Cultura, junto com os governos provinciais, desenvolveu diversas políticas com o objetivo de mitigar as consequências do isolamento social para o setor. Uma das medidas adotadas foi a criação do Fundo de Desenvolvimento para o Apoio a Espaços Culturais, aprovado pela resolução 260/2020 do Ministério da Cultura, de 09 de abril de 2020 (ARGENTINA, 2020a). Este fundo disponibiliza uma soma de 30 milhões de pesos, para gastos correntes dos centros culturais, dividida em três modalidades, de acordo com a capacidade de público, destinando, assim, um montante de 100 mil a 200 mil para cada espaço cultural (ARGENTINA, 2020b).

Outra medida adotada foi o fortalecimento de programas já existentes como: o Programa Pontos de Cultura que visa fortalecer as organizações coletivas e comunitárias, destinando 300 mil pesos para organizações instituídas como pessoas jurídicas, 150 mil pesos para coletivos e 700 mil para redes que articulam as organizações sociais. Outro programa que foi fortalecido foi o Programa "Beca Sostener Cultura" que tem por objetivo pagamento de bolsas para criação e formação artística (ARGENTINA, 2020c). 
Além disso, foram realizadas ações setoriais como: Fomento Solidario (ARGENTINA, 2020c), promovido pelo Instituto Nacional da Música que visou 1.020 benefícios de até 10 mil pesos para músicos. Já o Instituto Nacional do Teatro promove ações de subsídio para salas, produções teatrais e festivais. Cabe destacar que, além dos auxílios financeiros diretos, há editais e ações para a promoção da cultura nos meios digitais como o Programa Cultura Argentina em Casa que convoca mais de 300 artistas para elaborar conteúdos audiovisuais, destinando 18 mil pesos para cada um desses artistas (ARGENTINA, 2020d).

Em estados federalistas, como Brasil e Argentina, a complexidade da pandemia exige maior coordenação intergovernamental (ABRUCIO et al, 2020). Enquanto no Brasil observa-se uma desarticulação federalista e um protagonismo do legislativo, na Argentina, por exemplo, observa-se que as ações de coordenação federativa, tanto no controle da doença como nas políticas culturais, tiveram um impacto positivo no primeiro semestre. No entanto, o aspecto socioeconômico vivenciado pelo país tem sido um agravante para o crescimento de casos de Covid-19no país.

\section{O CASO ESPECÍFICO DE CUBA NO COMBATE AO NOVO CORONAVÍRUS}

Cuba é um dos países que melhor controlou a pandemia na América Latina, através de um rigoroso modelo de vigilância epidemiológica. Os primeiros casos positivos da COVID-19 foram diagnosticados, na ilha, no dia 11 de março de 2020, porém, desde fim de janeiro, o Ministro da Saúde Pública, junto com Chefe da Defesa Civil Nacional e outras organizações da Administração Central do Estado começaram a estabelecer um plano de prevenção e controle do novo coronavírus (CUBA, 2020a). Cuba reforçou a vigilância epidemiológica e preparou o sistema de saúde antes da aparição dos casos no território como afirma o diretor Nacional de Epidemiologia do Ministério da Saúde Pública (MINSAP),Francisco Durán García: "Continuamos a enfatizar a preparação de todo o sistema de saúde, desde os hospitais, às policlínicas, médicos de família e enfermeiros, em conjunto com os órgãos da Administração Central do Estado, que intervêm no plano intersetorial para o enfrentar vírus, particularizando na formação de pessoal de saúde " (ACOSTA, 2020)

A BBC News Mundo fez uma reportagem sobre o modelo de vigilância epidemiológica cubano a partir do relato de um jovem que contraiu a doença no fim de março. De acordo com a matéria de Miranda (2020a), o isolamento dos pacientes é acompanhado de um rigoroso rastreamento de contatos, que tiveram que ser isolados e declarados em vigilância. Este modelo de vigilância epidemiológica envolve ainda visitas de estudantes de Medicina e de Odontologia de casa em casa, com o objetivo de encontrar novos possíveis casos de contágio e um aplicativo denominado 


\section{AS POLÍTICAS PÚBLICAS CULTURAIS NO CONTEXTO PANDÊMICO: uma análise comparativa entre Brasil e América Latina}

Pesquisador Virtual, a partir do qual um cubano com acesso à internet pode informar que tem sintomas de contágio.

Uma das contribuições cubanas para enfrentar pandemia está também na indústria de biotecnologia. O Centro de Engenharia Genética e Biotecnologia (CIGB) desenvolveu uma tecnologia que aprimorou o processo de obtenção de um dos medicamentos incorporados pela China ao protocolo de tratamento da doença (CEPAL, 2020d). Cuba está desenvolvendo igualmente uma vacina contra 0 coronavírus, que começou a ser testada em humanos em 24 de agosto (MIRANDA, 2020b).

Até 0 fim de agosto, Cuba não tinha decretado nenhum confinamento obrigatório. As autoridades cubanas pediam apenas para sair de casa para o essencial e recomendaram o distanciamento físico e a higiene como principais formas de prevenção.A partir de primeiro de setembro, uma série de medidas foram decretadas na capital Havana para conter o aumento do número de casos.

No que se refere às medidas econômicas de auxilio financeiro à população, o site CubaDebate sistematizou algumas das medidas lançadas pelo Ministerio de Trabajo y Seguridad Social (MTSS). De acordo com a reportagem de 31 de março (MINISTERIO..., 2020), dada a paralisação das atividades laborais, o empregador prioriza o remanejamento dos trabalhadores para outras atividades, dentro ou fora da empresa. Quando não é possível realocá-lo, o trabalhador recebe uma garantia salarial equivalente a $100 \%$ do seu salário base diário durante o primeiro mês, e, após isso, a garantia é de $60 \%$ pelo período de paralisação. Além disso, em face da diminuição dos rendimentos do núcleo familiar em decorrência das medidas de distanciamento social, e, desde que comprovada a insuficiência de rendimentos para o pagamento dos serviços básicos, é concedido 0 benefício pecuniário temporário de assistência social de acordo com a composição do núcleo familiar.

Ainda de acordo com o site, os trabalhadores adoecidos pela COVID-19 recebem um subsídio. Durante a internação recebem $50 \%$ do salário médio recebido no ano imediatamente anterior à data da doença; se não forem internados e estiverem em situação de vigilância sanitária, recebem $60 \%$ desse salário médio. Os trabalhadores idosos ou fragilizados pelas suas condições físicas e, como medida preventiva, seja necessário o seu isolamento social, ganham uma garantia salarial equivalente a $100 \%$ do seu vencimento-base no primeiro mês, e $60 \%$ para os meses seguintes enquanto durar 0 isolamento.

Em relação às medidas ao setor cultural, o Ministerio de Cultura publicou em 16 de abril (CUBA, 2020b) as medidas de proteção salarial a todos os artistas e técnicos que integram o Instituto Cubano de Música e o Conselho Nacional de Artes do Espetáculo, tanto os que pertencem a unidades artísticas subsidiadas pelo Estado como os que operam em regime comercial. Os primeiros mantêm seus salários garantidos pelas mesmas normas lançadas pelo MTSS ditas acima. Os segundos são 
remunerados de acordo com as tabelas de vencimento regulamentados na Resolução 96 de agosto de 2019, em função da ocupação e do gênero artístico (PUEBLA, 2020). Em ambos os casos, os salários são pagos a $100 \%$ para o primeiro mês (abril) e a $60 \%$ a partir do segundo mês eenquanto perdurar a interrupção do trabalho. É importante assinalar que $70 \%$ dos cubanos adultos trabalham para o Estado e que Cuba tem um dos salários mínimos mais baixos da região, em torno de $\$ 400$ pesos cubanos (15 dólares mensais) $)^{14}$.

\section{CONSIDERAÇÕES FINAIS}

A pandemia do Covid-19 tem impactado de maneira colossal economias, relações interpessoais, hábitos, sistemas educacionais ao redor do mundo. No que se refere ao setor cultural, este impacto adquire proporções ainda maiores com o interrompimento de atividades artísticas e culturais e a avalanche de cancelamentos de festivais e eventos ligados à economia criativa. 0 isolamento social devido à pandemia não só modificou as formas de produção e consumo dos diversos elementos culturais e artísticos, como têm impactado de maneira profunda a economia do setor.

Nesse contexto, se tornou importante analisar as ações governamentais para o setor cultural em período de pandemia. Constatamos, a partir de análise comparativa, que a coordenação do poder executivo e intergovernamental é um aspecto importante para ações mais efetivas na América Latina. No entanto, observamos que a desigualdade social, o baixo investimento histórico em políticas públicas e, principalmente, em saúde, tem tornado a região a mais impactada pelo coronavírus. Contudo, a capacidade estatal de promover ações coordenadas e efetivas é um dos diferenciais dos países que tiveram um impacto menor da doença, no primeiro semestre.

Em relação às ações emergenciais para a cultura, verificamos que os países analisados promoveram medidas semelhantes como: auxílio financeiro direto aos artistas, editais de fomento, subsídios a espaços culturais e outros. Em todos os países pesquisados, com exceção do Brasil, observa-se uma ação efetiva dos ministérios da cultura para coordenar e promover tais ações, o que, apesar de alguns atrasos, como no Peru, possibilitou que os trabalhadores da cultura tivessem acesso às ações emergenciais, mesmo que de forma limitada, ainda no primeiro semestre de 2020.

No Brasil, a desarticulação federalista, como ressaltou Abrucioet al (2020), e o protagonismo do legislativo, como apontou Almeida (2020), também são evidentes no campo da cultura. Enquanto a Secretaria Especial de Cultura não promoveu nenhuma ação efetiva no combate aos impactos do Covid-19, observamos diversas ações sendo realizadas em estados e municípios. 0 portal da Confederação Nacional de Municípios (CNM) realizou um mapeamento de ações de estados para reduzir os impactos negativos da pandemia no setor cultural. O levantamento da CNM (2020), 
publicado no dia 25 de março e atualizado no dia 08 de abril, ressalta uma série de editais que foram divulgados nos estados da federação. Essas ações, no entanto, não foram vinculadas a uma política pública federal coordenada. Além disso, isso expressa uma reduzida preocupação do gestor federal em relação aos repasses de verba, já que a União tem maior capacidade financeira e política para gerir políticas públicas de forma mais equânime.

\section{REFERÊNCIAS}

ABRUCIO, Fernando Luiz et al. Combate à COVID-19 sob o federalismo bolsonarista: um caso de descoordenação intergovernamental, Revista de Administração Pública, Rio de Janeiro, n.54, v. 4, p. $663-677,2020$.

ACOSTA Lisandra Fariñas. COVID-19: Cuba refuerzavigilancia epidemiológica y preparacióndel sistema de salud. Entrevistado: Francisco Durán García CubaDebate, Havana, 2 marzo 2020. Disponível em: http://www.cubadebate.cu/noticias/2020/03/02/covid-19-cuba-refuerza-vigilanciaepidemiologica-y-preparacion-del-sistema-de-salud/\#.x3d4mcjkjiv. Acesso em: 5 ago 2020.

ALMEIDA, Acir, Relações executivo-legislativo e governabilidade à luz da crise da Covid-19. In: INSTITUTO DE PESQUISA ECONÔMICA APLICADA [IPEA]. Nota Técnica da Diretoria de Estudos e Políticas do Estado, das Instituições e da Democracia Brasília: IPEA, n. 34, abr. 2020.

ARGENTINA. Ministério de Cultura. FondoDesarrollar: Se extiende la convocatoria de apoyo económico para espaciosculturales. Buenos Aires: Ministerio de Cultura, 2020b. Disponível em: https://www.cultura.gob.ar/fondo-desarrollar-apoyo-economico-para-espacios-culturales-8911/. Acesso em: 20 ago. 2020.

ARGENTINA. Ministério de Cultura. Medidas para el sector de la cultura ante el COVID-19. Buenos Aires: Ministerio de Cultura, 2020d. Disponível em:https://www.cultura.gob.ar/medidas-en-el-sectorcultural-ante-el-covid-19-8932/. Acesso em: 26 ago 2020.

ARGENTINA. Ministério de Cultura. Programas e incentivos de asistencia a los sectores culturalesenel marco delcovid 19. Buenos Aires: Ministerio de Cultura, 2020c. Disponível em: https://www.cultura.gob.ar/media/uploads/30-04_covid-19_ministerio_de_cultura_-.pdf.Acesso em: 22 ago. 2020.

ARGENTINA. Ministério de Cultura. Resolución 260/2020, de 09 avril 2020. Boletín Oficial de La República Argentina, Buenos Aires: Ministerio de Cultura, 2020a. Disponivel em:https://www.boletinoficial.gob.ar/detalleAviso/primera/227697/20200411. Acesso em: 10 ago 2020.

BEL, PierinaPighi. Coronavírus: por que o Peru não consegue conter a covid-19, apesar de quarentena e investimentos. BBC News Mundo, [s.I.], 25 mai 2020. Disponível em: https://www.bbc.com/portuguese/internacional-52796852. Acesso em: 12 ago 2020.

BOLSONARO critica imprensa e fechamento de escolas e diz que crise passará. UOL Notícias, São Paulo,24 mar 2020. Disponivel em: https://noticias.uol.com.br/politica/ultimas-noticias/2020/03/24/covid19-bolsonaro-culpa-imprensa-por-panico-e-volta-a-falar-gripezinha.htm. Acesso em: 18 abr. 2020. 
BRASII. Lei $n^{0}$ 13.982, de 2 de abril de 2020. Altera a Lei $n^{0}$ 8.742, de 7 de dezembro de 1993, para dispor sobre parâmetros adicionais de caracterização da situação de vulnerabilidade social [...] Brasília: Congresso Nacional, 2020b Disponível em: https://www.in.gov.br/en/web/dou/-/lei-n-13.982-de-2-deabril-de-2020-250915958. Acesso em: 28 maio 2020.

BRASIL Ministério da Cidadania. Instrução normativa $n^{0}$ 5, de 20 de abril de 2020. Estabelece procedimentos extraordinários para captação, execução, prestação de contas e avaliação de resultados de projetos culturais financiados por meio do mecanismo incentivo a projetos culturais do Programa Nacional de Apoio à Cultura (Pronac) em razão da Covid-19 e em face das diretrizes fixadas pela União, estados, municípios e Distrito Federal. Brasília: Ministério da Cidadania, 2020c. Disponível em: https://www.in.gov.br/web/dou/-/instrucao-normativa-n-5-de-20-de-abril-de-2020-253341026. Acesso em: 30 maio 2020.

BRASIL. Decreto legislativo $n^{0}$ 6, de 20 de março de 2020. Reconhece, para os fins do art. 65 da Lei Complementar $n^{0} 101$, de 4 de maio de 2000, a ocorrência do estado de calamidade pública [...].Brasília: Senado Federal, 2020a. Disponível em: https://www.in.gov.br/en/web/dou/-/decretolegislativo-249090982. Acesso em: 21 maio 2020.

BRASIL. Decreto n ${ }^{0} 5.761$, de 27 de abril de 2006. Regulamenta a Lei no 8.313, de 23 de dezembro de 1991, estabelece sistemática de execução do Programa Nacional de Apoio à Cultura - PRONAC e dá outras providências. Diário Oficial [da] República Federativa doBrasil. Brasília, DF, 28 de abril de 2006, retificada em 11 de maio de 2006. Disponível em: http://www.planalto.gov.br/ccivil_03/_Ato20042006/2006/Decreto/D5761.htm. Acesso em: 9 jun. 2018.

BRASIL. Emenda Constitucional n.71, de 29 de novembro de 2012. Acrescenta 0 art. 216-A à Constituição Federal para instituir o Sistema Nacional de Cultura. Diário Oficial [da]República Federativa do Brasil, Brasília, DF, 2012. Disponível em: http://www2.camara.leg.br/legin/fed/emecon/2012/emendaconstitucional-71-29-novembro-2012774688-publicacaooriginal-138236-pl.html. Acesso em: 26 dez. 2018.

BRASIL. Lei $\mathrm{n}^{0}$ 13.978, de 17 de janeiro de 2020. Estima a receita e fixa a despesa da União para 0 exercício financeiro de 2020. Brasília: Presidência da República, 2020g. Disponível em: http://www.planalto.gov.br/ccivil_03/_ato2019-2022/2020/lei/L13978.htm. Acesso em: 10 dez. 2020.

BRASIL. Lei $n^{0} 14.017$, de 29 de junho 2020. Dispõe sobre ações emergenciais destinadas ao setor cultural a serem adotadas durante o estado de calamidade pública reconhecido pelo Decreto Legislativo $n^{0} 6$, de 20 de março de 2020. Brasília: Congresso Nacional, 2020f. Disponível em: http://www.planalto.gov.br/ccivil_03/_ato2019-2022/2020/lei/L14017.htm. Acesso em: 15 jul 2020.

BRASIL. Medida provisória $n^{0}$ 948, de 8 de abril de 2020. Dispõe sobre o cancelamento de serviços, de reservas e de eventos dos setores de turismo e cultura em razão do estado de calamidade pública [...]. Brasília: Presidência da República, 2020d. Disponível em: http://www.planalto.gov.br/ccivil_03/_Ato2019-2022/2020/Mpv/mpv948.htm. Acesso em: 20 maio 2020.

BRASIL. Ministério da Cidadania. Instrução normativa $n^{0}$ 6, de 29 de abril de 2020. Estabelece procedimentos extraordinários referentes aos parcelamentos de débitos regulados pelo art. 64 da Instrução Normativa n 2, de 23 de abril de 2019, do Ministério da Cidadania, em razão da Covid-19, face às diretrizes fixadas pela União, estados, municípios e Distrito Federal. Brasília: Ministério da Cidadania, 2020e. Disponível em: https://www.in.gov.br/web/dou/-/instrucao-normativa-n-6-de-29-deabril-de-2020-254678809. Acesso em: 2 jun. 2020. 
BRASIL. Ministério da Economia. Secretaria do Tesouro Nacional. Portaria $n^{0} 189$, de 23 de março de 2020. Brasília: Ministério da Economia, 2020h. Disponível em: https://www.in.gov.br/en/web/dou//portaria-n-189-de-23-de-marco-de-2020-249804104. Acesso em: 10 dez. 2020.

CAMPOS, Milagros. Perú: medidas contra la covid-19 y enfrentamientosconelcongreso. Agenda Pública - El País, Barcelona, 21 mayo 2020. Disponível em: http://agendapublica.elpais.com/perumedidas-contra-la-covid-19-y-enfrentamientos-con-el-congresol. Acesso em: 28 jul. 2020.

CARMO, Marcia. Como a Argentina conseguiu manter o número de mortes por covid-19 sob controle. BBC News Brasil, Buenos Aires, 03 ago 2020b. Disponível em: https://www.bbc.com/portuguese/internacional-53640342. Acesso em: 24 ago. 2020.

CARMO, Marcia. Coronavírus: Como o Chile precisou mudar estratégia contra a covid-19 após disparada de casos. BBC News Brasil, Buenos Aires,18 jul2020a.Disponível em: https://cultura.uol.com.br/noticias/bbc/53415588_coronavirus-como-o-chile-precisou-mudar-estrategiacontra-a-covid-19-apos-disparada-de-casos.html. Acesso em: 15 ago. 2020.

CGU - CONTROLADORIA GERAL DA UNIÃO. Portal da Transparência. Disponível em: http://www.portaltransparencia.gov.br. Acesso em: 16 dez. 2020.

CHARLEAUX João Paulo. O avanço descontrolado da pandemia no Peru e no Chile. Nexo, São Paulo, 19 jun 2020 Disponível em: www.nexojornal.com.br/expresso/2020/06/19/O-avan\%C3\%A7odescontrolado-da-pandemia-no-Peru-e-no-Chile. Acesso em: 22 ago. 2020.

CHILE. Gobierno promulga Ley que creaellngreso Familiar de Emergencia que vaenayuda de casi 2 millones de hogares, Chile reports, Santiago, 15 mayo 2020a. Disponível em :

https://chilereports.cl/noticias/2020/05/14/gobierno-promulga-ley-que-crea-el-ingreso-familiar-deemergencia-que-va-en-ayuda-de-casi-2-millones-de-hogares. Acesso em: 18 ago. 2020.

CHILE. Ministerio de las Culturas, las Artes y elPatrimonio. Ministerio de las Culturas destinará 15 mil millones de pesos para apoyar a artistas y organizaciones ante emergencia por coronavirus. Santiago, 2020b. Disponível em: https://www.cultura.gob.cl/institucional/ministerio-de-las-culturas-lasartes-y-el-patrimonio-destinara-15-mil-millones-de-pesos-para-apoyar-a-artistas-y-organizaciones-anteemergencia-por-coronavirus/. Acesso em: 13 jul. 2020.

CHILE. Seremi de las Culturas, las Artes y elPatrimonio, Región de Valparaíso, las Artes y el Patrimonio. Plan de EmergenciaArtística:ValparaísoElige Cultura En Casa.[s.l.], 2020c. Disponível em: https://www.cultura.gob.cl/wp-content/uploads/2020/05/bases-valparaiso-elige-cultura-en-casaaa.ee-120520-2.pdf. Acesso em: 15 jul. 2020.

CODATO, Adriano et al. a instabilidade da "equipe econômica" do Governo brasileiro In: PIRES, Roberto; LOTTA, Gabriela, OLIVEIRA, Vanessa Elias de (org.) . Burocracia e políticas públicas no Brasil: interseções analíticas. Brasília: Ipea : Enap, 2018.

COMISSÃO ECONÔMICA PARA A AMÉRICA LATINA E O CARIBE [CEPAL]. Estructura comercial y medidas económicas ante la pandemia de COVID-19 enCentroamérica, Cuba, Haití, México y la República Dominicana. Ciudad de México: CEPAL, 2020d. Disponível em: https://repositorio.cepal.org/bitstream/handle/11362/45785/1/S2000473_es.pdf. Acesso em: 12 ago. 2020. 
COMISSÃO ECONÔMICA PARA A AMÉRICA LATINA E O CARIBE [CEPAL]. América Latina y el Caribe ante la pandemia del COVID-19: Efectos económicos y sociales. Informe Especial covid-19, n.1, [s.I.], CEPAL 2020a. Disponível em:

https://repositorio.cepal.org/bitstream/handle/11362/45337/6/S2000264_es.pdf. Acesso em: 25 jul. 2020.

COMISSÃO ECONÔMICA PARA A AMÉRICA LATINA E O CARIBE [CEPAL]. Panorama Social da América Latina, 2019. Resumo executivo (LC/PUB.2020/1-P), Santiago: CEPAL, 2020b. Disponível em: https://repositorio.cepal.org/bitstream/handle/11362/45090/1/S1900909_pt.pdf. Acesso em: 5 ago. 2020.

COMISSÃO ECONÔMICA PARA A AMÉRICA LATINA E O CARIBE [CEPAL]. , Balanço Preliminar das Economias da América Latina e do Caribe, 2020. Resumo executivo (LC/PUB.2020/18), Santiago, 2020c.

COMISSÃO ECONÔMICA PARA A AMÉRICA LATINA E O CARIBE [CEPAL]. Panorama Social da América Latina 2020, (LC/PUB.2021/3-P), Santiago, 2021.

CONFEDERAÇÃO NACIONAL DE MUNICÍPIOS (CNM). CNM faz mapeamento das medidas estaduais para enfrentar os impactos do coronavírus no setor cultural. Brasília, 25 mar 2020. Disponivel em: https://www.cnm.org.br/comunicacao/noticias/cnm-faz-mapeamento-das-medidas-paraenfrentar-os-impactos-do-coronavirus-no-setor-cultural Acesso em: 18 maio 2020.

CRUZ, Carolina. Lei Aldir Blanc: artistas e produtores do DF protestam por incertezas no auxílio emergencial. G1, Distrito Federal, 23 nov. 2020. Disponível em: https://g1.globo.com/df/distritofederal/noticia/2020/11/23/lei-aldir-blanc-artistas-e-produtores-do-df-protestam-por-incertezas-noauxilio-emergencial.ghtml. Acesso em: 19 dez. 2020.

CUÁLES son todos losbonos que está entregando elGobierno y cómocobrarlos, RPP Noticias, San Isidro, 25 ago 2020. Disponível em: https://cutt.ly/rgkBUkQ. Acesso em: 3 set. 2020.

CUBA Ministerio de Cultura. Medidas adoptadas por el Ministerio de Cultura para laprevención y enfrentamiento a la \#Covid-19. Havana, 16 abr. 2020b. Disponível em:

http://www.ministeriodecultura.gob.cu/es/actualidad/noticias/medidas-adoptadas-por-el-ministerio-decultura-para-la-prevencion-y-enfrentamiento-a-la-covid-19. Acesso em: 4 ago. 2020.

CUBA. Ministerio de Salud Pública. Cuba fortalece el sistema de vigilancia para contenerlaintroduccióndelnuevocoronavirus. Havana, 29 enero2020a. Disponível em: https://salud.msp.gob.cu/cuba-fortalece-el-sistema-de-vigilancia-para-contener-la-introduccion-ydiseminacion-del-nuevo-coronavirus/. Acesso em: 3 ago 2020.

FREIRE, Vinícius Torres. Lei Aldir Blanc dá a governos muita verba e pouco tempo para gastar. Folha de S. Paulo, São Paulo, 19 dez. 2020. Disponível em: https://www1.folha.uol.com.br/seminariosfolha/2020/12/lei-aldir-blanc-da-a-governos-muita-verba-epouco-tempo-para-gastar.shtml. Acesso em: 19 dez. 2020.

LINHARES, Paulo de Tarso Frazão Soares; RAMOS, Tarcila Queiroz; MESSENBERG, Roberto Pires. Inovação institucional na coordenação federativa para enfrentamento e saída do surto de covid-19 In: INSTITUTO DE PESQUISA ECONÔMICA APLICADA [IPEA]. Nota Técnica da Diretoria de Estudos e Políticas do Estado, das Instituições e da Democracia, n.41, jul. 2020, Brasília: IPEA, 2020. 
MINISTERIO de Trabajo: Tratamiento laboral, salarial y de seguridad social por la COVID-19. Havana, 31 marzo 2020. Disponível em: http://www.cubadebate.cu/noticias/2020/03/31/ministerio-de-trabajotratamiento-laboral-salarial-y-de-seguridad-social-por-la-covid-19/\#.X4teQdVKjIV. Acesso em: 10 ago. 2020.

MIRANDA, Boris. Coronavirusen Cuba: cómo funciona elagresivo modelo de vigilancia epidemiológica contra la covid-19. BBC News Mundo, [s.I.],1 mayo 2020a. Disponível em:

https://www.bbc.com/mundo/noticias-america-latina-52496344. Acesso em: 20 jul 2020.

MIRANDA, Boris. Vacuna para elcoronavirus | Soberana 01: la fórmula de Cuba contra la covid-19 que comienza a probarseen humanos. BBC News Mundo,[s.l.], 24 agosto 2020. Disponível em: https://www.bbc.com/mundo/noticias-america-latina-53871212 Acesso em: 6 set. 2020.

ORGANIZAÇÃO DAS NAÇÕES UNIDAS [ONU]. Análisis inicial de lasnaciones unidas Covid-19 en argentina: Impacto socioeconómico y ambienta. [S.I.], 2020. Disponível em:

https://www.onu.org.ar/stuff/Informe-COVID-19-Argentina.pdf. Acesso em: 10 set. 2020.

PALOTTI, Pedro Lucas de Moura. Estratégias de seleção e substituição de ministros de Estado no presidencialismo de coalizão brasileiro: perfil, alocação e rotatividade. Tese (doutorado em ciência política) - Programa de Pós-Graduação em Ciência Política da Universidade de Brasília (UnB).Universidade de Brasília, Brasília, 2017.

PERU. Decreto de urgencia n. 058, de 20 mayo 2020. Aprueban mecanismos de amortiguamiento para mitigar losefectos económicos enel sector cultura producidosenel contexto de laemergenciasanitaria por el covid-19. Diario oficial delbicentenarioel peruano, Lima, 2020.Disponível em:https://busquedas.elperuano.pe/normaslegales/aprueban-mecanismos-de-amortiguamiento-paramitigar-los-efec-decreto-de-urgencia-n-058-2020-1866605-1/. Acesso em: 25 jul.2020

PIÑERA ordenó toque de queda en todo Chile entre lãs 22:00 y las 05:00 horas. Cooperatva.cl., Santiago, 22 marzo 2020. Disponível em:

https://www.cooperativa.cl/noticias/sociedad/salud/coronavirus/pinera-ordeno-toque-de-queda-en-todochile-entre-las-22-00-y-las-05-00/2020-03-22/103606.html. Acesso em: 20 jul. 2020.

POMPEU, Lauriberto. Guedes anuncia voucher de $\mathrm{R} \$ 200$ para trabalhador informal. Congresso em foco, Brasília, 18 mar 2020. Disponível em: https://congressoemfoco.uol.com.br/governo/guedesanuncia-voucher-de-r-200-para-trabalhador-informal/. Acesso em: 24 jul. 2020.

PUEBLA, Thalía Fuentes. Ante la COVID-19: Artistas cubanos tambiénrecibirántratamiento salarial. CubaDebate, Havana, 17 abril 2020. Disponível em:

http://www.cubadebate.cu/especiales/2020/04/17/ante-la-covid-19-artistas-cubanos-tambien-recibirantratamiento-salarial/\#.X3ECA8JKjIV. Acesso em: 30 ago 2020.

ROMÁN, Cecilia. La terceraversióndel IFE: más simple y más hogares incluídos. Pauta, Santiago, 31 jul 2020. Disponível em: www.pauta.cl/economia/como-funciona-el-ife-3-reduccion-ingresos-formalesen-chile. Acesso em: 17 ago 2020.

UNESCO. Cultura \& Covid-19 - impacto e respuesta (número especial). [s. I.], 2020. Disponível em: https://es.unesco.org/sites/default/files/issue_12_es.1_culture_covid-19_tracker.pdf. Acesso em: 20 ago. 2020. 


\section{WORLD HEALTH ORGANIZATION [WHO].WHO Coronavirus Disease (COVID-19) Dashboard. Disponível em: https://covid19.who.int/. Acesso em: 1 set. 2020.}

\section{Notas}

10 primeiro ministro, o médico Luiz Henrique Mandetta, deixou o cargo em 16 de abril de 2020 e o segundo, Nelson Teich, em 15 de maio do mesmo ano. De 16 de maio de 2020 a 23 de março de 2021, o Ministério é ocupado pelo General do Exército Brasileiro, Eduardo Pazuello, que primeiro assumiu o cargo interinamente e, em 16 de setembro, tomou posse como ministro da saúde oficial. No momento da revisão da escrita desse ensaio (23 de maio de 2021), o Ministério é ocupado por Marcelo Queiroga.

2 Dados referentes a 1 setembro de 2020. https://covid19. who.int/table

3 Durante o governo Bolsonaro (2019-2020), a secretaria de cultura já teve diferentes comandos: Henrique Pires (jan-ago 2019), Ricardo Braga (set-nov 2019), Roberto Alvim (nov 2019-jan 2020), José Paulo Martins (Interino de jan-mar 2020), Regina Duarte (Mar-jun 2020) e o atual Mário Frias.

${ }^{4}$ A Lei foi alterada, em 2021, através da Lei 14.150, de 12 de maio de 2021 que prorrogou o prazo de utilização dos recursos para estados e municípios para o ano de 2021; estabeleceu o prazo de 180 dias, a contar do início das atividades culturais de cada cidade e região, para as contrapartidas dos espaços artísticos e culturais que receberam subsídio (de acordo com o inciso II do art. 2 da Lei 14.017), e priorizou a concessão de recursos no âmbito do Programa Nacional de Apoio à Cultura (Pronac) aos projetos culturais que possam ser transmitidos pela internet ou pelas redes sociais. A lei 14.150 foi sancionada com oito vetos do presidente da República, dentre os vetos, se encontrava aprorrogação por dois anos dos prazos para aplicação dos recursos.

${ }^{5}$ Compositor e escritor Aldir Blanc, que morreu em maio, vítima da Covid-19.

${ }^{6}$ Cabe observar que o SNC carece de uma regulamentação, prevista no $\S 3^{\circ}$ da Emenda Constitucional n. 71/2012. O PL 4271/2016, que tinha esse fim, foi arquivado na Câmara dos Deputados, no dia 31/01/2019.

${ }^{7}$ Como a Lei Aldir Blanc ainda está execução, não objetivamos analisá-la. No entanto, é importante observar a ocorrência de diversos problemas associados à implementação da Lei, como ressaltam reportagens jornalísticas FREIRE, 2020; CRUZ, 2020 entre outros.

${ }^{8}$ Cada cidadão tem direito a duas por semana e ela pode ser obtida virtualmentepelo número de série (ou verificador) da carteira de identidade.

${ }^{9}$ A primeira parcela do bônus familiar universal era destinado a famílias que não tinham vínculo empregatício no setor público ou privado e não considerava outros beneficiários de outros subsídios. Já a segunda parcela, anunciada no dia 28 de julho, visava atingir maior número de famílias ao considerar os beneficiários de outros programas (CUÁLES..., 2020).

${ }^{10}$ Dados referentes a 1 setembro de 2020. https://covid19.who.int/table

${ }^{11}$ Dados referentes a 1 de setembro de 2020. https://covid19.who.int/table

${ }^{12}$ Em agosto, houve um incremento do número de casos da doença.

${ }^{13}$ No dia 31 de agosto, a Argentina contabilizava 401 mil casos confirmados e 8.401 mortos por coronavírus. https://covid19.who.int/table

${ }^{14}$ Conforme os dados disponível no wikipédiahttps://es.wikipedia.org/wiki/Plantilla:Salarios_m\%C3\%ADnimos_en_Latinoam\%C3\%A9rica 